\title{
POLICY STATEMENT: MINIMALLY INVASIVE CORONARY ARTERY BYPASS SURGERY
}

\author{
STS/AATS AD HOC COMMITTEE ON NEW TECHNOLOGY ASSESSMENT
}

$\mathrm{M}$ inimally invasive coronary artery bypass (MICAB) procedures with or without cardiopulmonary bypass (CPB) are approaches for surgical coronary revascularization designed to reduce operative trauma, speed patient recovery, allow faster return to normal activity, and achieve cost containment as compared with conventional coronary bypass grafting.

Minimally invasive direct coronary bypass (frequently referred to as MIDCAB) is an approach that does not use CPB or cardioplegia. Most commonly, a small left anterior thoracotomy is made and the left internal thoracic artery is harvested and anastomosed to the left anterior descending coronary artery on the beating heart. Although single-vessel bypass has been done in more than $90 \%$ of the cases, multiple grafting can be accomplished in some circumstances. The use of complete sternotomy with multivessel bypass on the beating heart without $\mathrm{CPB}$ is also an option (frequently referred to as OPCAB), and some have referred to this as "minimally invasive" because CPB is not used. Another approach to minimal-access coronary artery bypass grafting is to employ CPB. In this instance, the operation (frequently referred to as PA-CAB) is performed through a limited thoracic incision, but also using PortAccess technology. CPB is established through peripheral cannulation. Cardioplegia is administered after aortic occlusion with an Endoaortic balloon clamp, and Port-Access techniques are used for insertion of thoracoscopic and special instruments. Finally, minimally invasive coronary artery bypass can also be performed with CPB through the same incisions, but without aortic occlusion, using ventricular fibrillation and immobilization of the coronary arteries.

The premise for adopting these less invasive approaches to coronary grafting is that patient morbidity can be reduced without reducing the safety or efficacy of the coronary bypass operation. At this early stage in the minimally invasive coronary bypass experience, considerable data are being generated. Clearly, MICAB is misused if it is performed for cosmesis, as a result of

J Thorac Cardiovasc Surg 1998;116:887-8

Copyright $\odot 1998$ by Mosby, Inc.

0022-5223/98 \$5.00+ $0 \quad \mathbf{1 2 / 1 / 9 3 6 2 7}$ peer pressure, for marketing purposes, or without proper training and supervision. The STS/AATS Committee on New Technology specifically condemns the performance of MICAB only for marketing purposes. The results obtained by using conventional open techniques must be matched by MICAB techniques.

MICAB is essentially a reconfiguration of a number of established and accepted cardiac surgical techniques using new incisional and anatomic approaches, rather than a new procedure to establish myocardial revascularization. Minimally invasive techniques continue to evolve and may now include a variety of stabilization and/or visual enhancement systems. MICAB must undergo rigorous evaluation for comparison to the established results of conventional coronary bypass. Patients must be fully informed of the differences between conventional grafting and the minimal-access grafting. Surgeon and center experience must be discussed. Graft patency data should be collected to help identify differences that may ultimately become significant and to establish the role of these techniques in the surgical treatment of coronary artery disease.

The different approaches required for MICAB and the problematic issues of performing precise anastomoses either on the beating heart or through small incisions on the arrested heart during CPB make the issue of surgical education particularly important. As the various approaches to MICAB evolve, a profusion of new techniques and equipment has appeared. A surgeon wishing to adopt these new techniques or technologies should attend one or more CME approved courses that conform to the STS/AATS Ad Hoc Committee on New Technology Assessment educational guidelines. These courses should include didactic sessions, and may include video sessions, ideally interspersed with laboratory experience to master specific techniques. Observation of minimally invasive surgery at experienced centers is now possible and is strongly encouraged.

MICAB will continue to evolve over the next several years and new or hybrid procedures and new technologies will likely emerge. As this occurs, it is incumbent on practitioners to appropriately educate themselves, as well as to document and disseminate new information. The Joint Committee strongly recommends that performance of these procedures be currently restricted to 
established cardiac surgical programs staffed by boardcertified cardiothoracic surgeons who are skilled in the performance of conventional cardiac operations. It is also strongly recommended that these procedures be monitored closely for morbidity and mortality by established hospital quality assurance committees. Such monitoring should include documentation of complications and long-term outcome, especially as these factors relate to conventional coronary bypass surgery. The STS/AATS Ad Hoc Committee on New Technology Assessment is available to consult with organizations such as the National Institutes of Health, Food and Drug Administration, Health Care Financing Administration, Joint Commission on Accreditation of Healthcare Organizations, and American Board of Thoracic Surgery on questions relating to the performance and evaluation of the operation, as well as the training of the surgeons who perform MICAB.
STS/AATS Committee on New Technology Assessment Lawrence H. Cohn, MD, Chairman W. Randolph Chitwood, MD James Gordon Dralle, MD Robert W. Emery, MD Rick A. Esposito, MD James D. Fonger, MD Richard F. Heitmiller, MD Larry K. Kaiser, $M D$

Rodney J. Landreneau, MD

Toni E. Lerut, $M D$

Bruce W. Lytle, MD Michael Mack, MD

Lawrence R. McBride, MD

Bruce A. Reitz, MD

Hartzell V. Schaff, MD

Valavanur A. Subramanian, MD Jan L. Svennevig, $M D$ Julie A. Swain, MD Daniel J. Ullyot, MD 